\title{
Comprehensive Analysis of Technical Management of Urban Underground Rail Transit Construction: A Case Study of Chengdu Metro Line 17
}

\author{
Zhang $\mathrm{Yu}^{1, *}$ \\ ${ }^{1}$ China Communications construction company Ltd, Beijing, China
}

\begin{abstract}
With the advancement and strengthening of urbanization, supercities are continually emerging; however, the traffic problems that accompany this growth actually hinder urban development. Thus, construction of an urban underground rail transit system is an important civil project for utilization of urban underground space. In particular, numerous railway and tunnel projects have been implemented in China during the past few decades with great progress made in rail transit construction technology. Nonetheless, many technical challenges have also been encountered in areas of design, construction, safe operation, and maintenance. To examine such problems, the Phase I project of China's Chengdu Metro Line 17 is comprehensively analyzed as a case study, and an in-depth discussion is given on the construction technology and technical management practices. The data obtained in the management process are classified and archived to form a complete dataset of technical project management. After the project is completed, the experience and lessons in technical management will be summarized to form reference material for similar projects in the future.
\end{abstract}

\section{Introduction}

With the strengthening of urban spatial interaction, the urban agglomeration and the interior structures of cities have changed in scale from simple hierarchical to complex network structures. Chengdu-Chongqing urban agglomeration is a key state-level urban agglomeration in China. Compared with coastal urban agglomerations, its urban development level and comprehensive economic power are relatively weak ${ }^{[1]}$. The spatial resources and urban structure of Chengdu-Chongqing urban agglomeration are affected mainly by the geographical location and vehicular traffic. With the implementation of a series of national strategies, such as urban agglomerations and national central cities, underground engineering construction in Chengdu City has entered a high-speed development stage. In particular, the planning and construction of rail transit systems ensure the future development potential of large cities. At present, high-speed rail systems have been completed or planned within the tri-circle area of Chengdu City to achieve rapid connection between districts and counties. This city, which is the capital of Sichuan Province, has experienced the most intensive external and internal transportation construction in the province. The most important objective of transport projects in Chengdu City is to provide a foundation for future urban expansion by constructing basic transportation facilities with internal connections to join all districts, counties, and cities. In the "14th Five-Year
Plan" of Chengdu City, development of a multi-style, high-quality rail network is taken as the direction of future development ${ }^{[2]}$.

Chengdu Rail Transit Line 17 is an important western express line in urban rapid rail transit system of Chengdu $\mathrm{City}^{[3]}$. The central urban area, Wenjiang District, and Dongsheng Street of Shuangliu District are connected through the main branch line, which further enhances the rapid connection between the peripheral areas and the central urban area. Line 17 begins at Dashi West Road Station of Line 5 on the First Ring Road and extends to Wenjiang District and Dongsheng Town of Shuangliu District after exiting the Fourth Ring Road along Chengxin Expressway. The line has a total length of $49.6 \mathrm{~km}$ and includes 19 stations.

The technical management of a rail transit project involves the integration of technology and management. Reasonable technical management regulations can promote the scientific and technological progress of the project and continuously improve the labor productivity and economic benefits of the enterprises. As an important part of project management of a subway project and the foundation of its entire process of construction and production, detailed and precise technical management guidelines should be adhered to throughout the cycle of the project. Taking the Phase I project of Chengdu Metro Line 17 as an example, this study summarizes the practices of technical management and safe operation and maintenance of a subway project

* Corresponding author: 5030821@qq.com 
to provide a reference for the future development of urban rail transit construction in Chengdu City.

\section{Main lessons learned in technical management}

\subsection{Technical management before commencement of the project}

The preparation of subway construction is extremely important and requires the attention of the entire project department staff. All forces should be concentrated to ensure the completion of the preparation in the shortest time, thus laying a solid foundation for the early commencement of the project.

Before the project construction, technical planning should be well implemented, and the main risk sources of the project should be effectively identified. In addition, solutions should be put forward, and a construction organization design should be prepared to provide guidance for the orderly advancement of the project. In addition, various technical management systems of the project should be prepared according to relevant technical documents, and the division of responsibilities should be clarified, thus ensuring that all departments can perform their duties and jointly promote the work of the project. Moreover, technical training and communication work should be implemented in advance, and the technical talents of the project department should be actively cultivated. In particular, the technical backbone of the project department should be cultivated so as to reserve enough talent resources for the project construction.

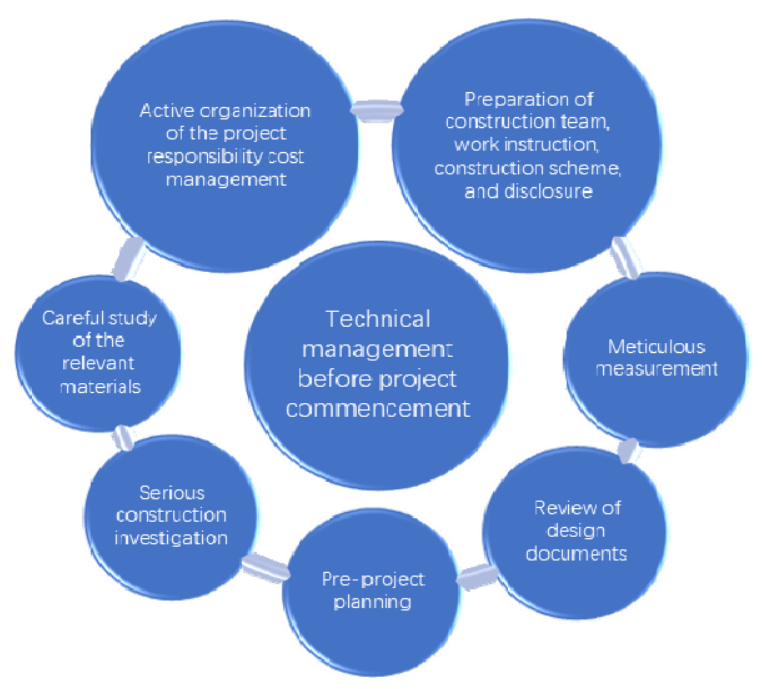

Fig. 1. Below the figure. Originally designed two-way, fourlane traffic relief road

\subsection{Technical management during construction}

In the construction process, the testing and measurement work should be improved, and attention should be paid to the model guide project, key control technology, and quality management. Safety management should be conducted in strict accordance with the safety management documents ${ }^{[4]}$. Active communication regarding the design according to the site conditions should be ensured and comprehensive services should be provided for the site.

\subsubsection{Mentoring and training}

Technical project managers are mostly new personnel who have recently graduated and taken the position. To effectively perform the technical work of the project, it is necessary to plan and manage excellent young management talents and to train new managers through methods such as mentoring and by actual operation on construction sites.

\subsubsection{Quality testing and measurement}

Testing and measurement are key to the technical management of the project. Testing and raw material inspection are strictly implemented according to the measurement and test management methods implemented by construction companies. Thus, the construction quality is ensured from the source. The measurement work is also reviewed in strict accordance with the review system to avoid measurement errors and economic losses.

\subsubsection{Model guide and quality control management}

During the project construction, technicians are organized to timely formulate a model scheme according to the design requirements, specifications, and acceptance standards, and a model is constructed according to the scheme. The construction parameters are determined in strict accordance with the test results for on-site construction. Equal attention is paid to project construction quality and construction progress and safety, which are important in project management. Construction standards are determined before each oneway project begins. After completing a model project, a model guide is adopted; the staff of each construction shift is organized for study and observation; and the construction process requirements, key points of quality control, and quality standards achieved are explained. Through the model guide, the technical management level is improved. In addition, the technical personnel are provided with perceptual knowledge of construction technology, process requirements, and quality control to increase their on-site technical management experience. The project quality control has a dual purpose. For important processes, the project department appoints special personnel to take charge of monitoring and control, as well as to provide technical guidance and ensure quality control for the on-site technicians so as to avoid accidents caused by personal mistakes.

\subsubsection{Scheme optimization design and site work}

A certain degree of error is present in some drawings of the design institute, which leads to inconsistencies in the on-site construction. Thus, special personnel are 
assigned to communicate with the design institute in time to address any problems at the site, which optimizes the design to avoid construction delays and save construction costs. In the process of construction, the project department improves all types of data according to the planning differences to lay the foundation for design changes. This also serves preparation for changes and claim ${ }^{[5]}$.

The relief road in Phase I of the Fengxihe Station construction of the Chengdu Metro Line 17 project was originally designed to be a two-way, four-lane road, as shown in Figure 2. However, because the construction site was very narrow, the relief road was finally optimized as a one-way, two-lane road, as shown in Figure 3, after communicating with the Traffic Management Department and Design Institute of Wenjiang District, which expanded the construction site.

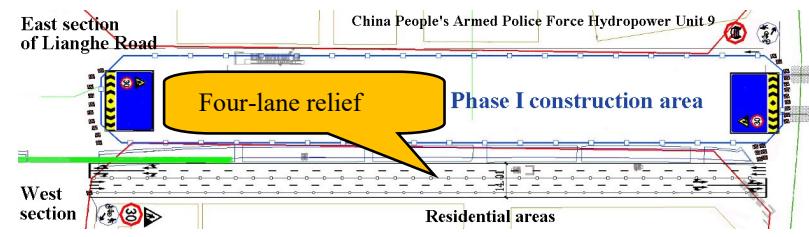

Fig. 2 Originally designed two-way, four-lane traffic relief road

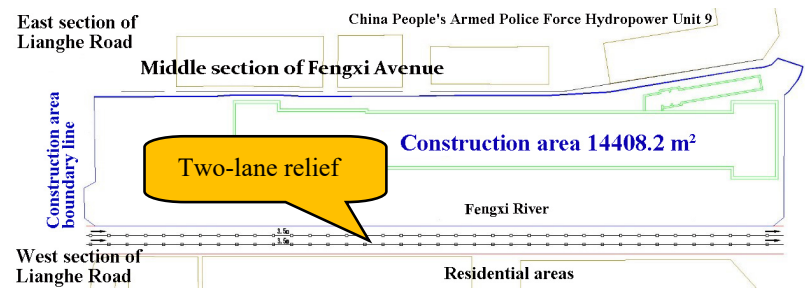

Fig. 3. Optimized two-way, two-lane traffic relief road Below the figure.

\subsection{Final stage of technical management}

Even more attention should be emphasized on technical management when the project has entered the final stage so as to avoid wasting the previous efforts. In the final stage, the construction at the site should still be well maintained. The protection of on-site finished and semifinished products should be enhanced to ensure that no damage occurs prior to the completion and handover of the project. The remaining parts of the project should be addressed in time. The detailed plans should be followed and realized one by one, including those regarding the construction period and the resource allocation of personnel, materials, and machinery. The remaining parts of the project are generally small and scattered, so the cost should be saved to the maximum extent.

\section{Comprehensive evaluation of safety}

In terms of safety management, the project department fully implements the policy of "safety first, prevention first, and comprehensive treatment," actively publicizes the safety concept of "giving priority to fulfilling safety responsibility," and always makes safe production the most important factor. When the construction team enters the site, the project department has already provided safety education, vigorously promoted the knowledge of safety production, enhanced the awareness of safety responsibility, and fully understood the importance of safety production from the ideological and conceptual perspectives. Providing safety training for the mobilization team and conducting lectures on safe production improves the safety awareness of the construction personnel. The pre-job training of the operators is fully implemented, covering each aspect.

Various safety management systems ${ }^{[6]}$ for the project are established and improved upon. The project department is focused on strengthening safety education, training, and disclosure; increasing on-site safety investment; and implementing various safety management systems such as daily, weekly, and monthly inspection of safety and environmental protection systems. In addition, emergency drills are conducted and weekly meetings are held to discuss the implementation of various special safety activities in depth. Strict attention to safety is provided by management to ensure safe production. The managers implement construction standards, complete various safety production objectives, and realize the safe and stable development of the entire project.

\section{Comprehensive evaluation of quality}

\subsection{Quality data}

The Yongyi Depot of Chengdu Metro Line 17 includes two unit projects, Yongyi Depot construction and base project and Yongyi Depot main substation. The former includes 41 sub-unit projects, 124 sub-projects, and 1030 sub-divisional projects, and the latter consists of 6 subunit projects, 34 sub-project projects, and 166 subdivisional projects ${ }^{[7]}$. The partition of each division is reasonable, and the records reflection status of the construction process is complete. All of the master control projects meet the qualification requirements, and the general projects meet the design and construction specifications. Comprehensive documents including technical documents and records of foundation treatment, construction data, concealed project acceptance information, engineering quality evaluation, and completion acceptance have been sorted and completed according to the requirements of volume formation. The documents and materials are complete.

\subsection{Final stage of technical management}

The project department establishes quality objectives and a quality assurance system at the beginning of the project. Besides designating quality inspection personnel at all levels of the project department, the quality monitoring stations and supervisors also strictly supervise the quality at the site and conduct weekly construction quality inspections every week to ensure the quality of each working procedure at the site ${ }^{[8]}$.

During the construction of each working procedure, the project department ensures that full-time quality inspectors conduct on-site engineering monitoring of procedures such as template installation, steel bar 
processing and installation, concrete pouring, foundation excavation and pit filling, road construction compaction, and measurement of compaction thickness and elevation. Each on-site working procedure is strictly controlled and accepted with the approval of the supervisor; a new working procedure can begin only after the current procedure is accepted. To ensure the orderly progress of each process on-site, a quality acceptance team should be formed to make suggestions and evaluations on each part of the project through inspection and acceptance.

\subsection{Quality inspection}

\subsubsection{Control of project raw materials and semi- finished products}

- All raw materials entering the site are strictly controlled in terms of quality, and their qualification certificates are checked in detail. In conjunction with the materials and the equipment departments, the quality inspection department and the supervision unit collect samples for inspection. In the case of unqualified materials, the materials department will be notified to clear the unqualified materials in time ${ }^{[9]}$. It is strictly forbidden to use unqualified materials in the project.

- The project department supervises the activity of the commercial concrete company to control the quality of concrete, check the quality of raw materials, and recheck the testing indicators of various materials to ensure the use of high-quality concrete and normal production at the construction site.

- The project department supervises the quality management of semi-finished products and components, sends samples for testing in time, and checks to ensure that the testing indicators meet the construction quality requirements.

\subsubsection{Control of on-site testing and inspection of the project}

- The difficulty in testing the 21 buildings of Yongyi Depot lies mainly in determining whether the foundation treatment meets the bearing capacity requirements and ensuring that the compactness of backfill meets the design requirements ${ }^{[10]}$. Then, the concrete strength and reinforced protective layer are tested to ensure that they meet the design specifications.

- Bi-directional index control testing should be conducted on subgrade engineering, road engineering, inspection tasks, and filling quality control; the compaction index and K30 plate load test should meet the design specifications. When paving the cement stabilization and asphalt layers, all test indices should be applied, and the results should meet the requirements. The subgrade and road quality of the project are well controlled with no settlement occurrence.

- The secondary structure and decoration inspection and auxiliary project inspection are also difficult tasks. Thus, they should be checked and tested according to the specifications to ensure that the quality materials are applied in the project.
- In terms of the testing, if quality defects or nonconforming products are present in the construction with the operation team, a rectification notice will be timely issued to urge the correction, which is then monitored.

\subsubsection{Project quality management}

The project department actively participates in QC team activities of the project. It is required to conduct multiple test analyses to obtain test results, meet QC activity requirements, and improve the construction quality standards, thus increasing the benefits of the project, improving the construction technology, and controlling quality risks.

\subsubsection{Testing and acceptance data of the project}

The project department communicates with the testing unit in time, issues a report for tests completed at the construction site, collects and files the data, and meets the handover requirements for completion acceptance.

The overall quality of the project is controllable ${ }^{[11]}$. The project construction period is tight, and the task of construction inspection is difficult. To ensure the construction quality, the general contractor works in conjunction with the supervision and inspection units coordinated by the project department to jointly work on the project production and to promote its progress. In the testing and inspection conducted by a third-party testing unit and the supervision testing unit, the raw materials at the construction site and various on-site test indicators are evaluated to ensure that they meet the design requirements, thus guaranteeing that the project quality control achieves good results.

\section{Conclusions}

In the daily management work, technical management is conducted according to related requirements at all levels, including the preparation of the construction scheme, construction technical disclosure, and construction summary. In addition, technical problems should be discussed and treated, and technical training should be provided. The data obtained in the management process are classified and archived to form a complete dataset of technical project management. After the project is completed, the experience and lessons in technical management will be summarized to form reference material for similar projects in the future.

According to this analysis and summary, technical management is one of the key tasks of the entire project. Whether the project can be advanced as scheduled and the quality can be effectively guaranteed is closely related to technical management, which is applied throughout the construction process. Therefore, research on construction technology and safety management will continue in the future, and relevant personnel should closely study the results. 


\section{References}

1. Zhang Junlin, Zhang Shiliang. Development strategy of medium and low volume rail transit system from the perspective of urbanization [J]. China Collective Economy, 16, 11 (2021).

2. Ji Guofu. Thinking on the construction of urban (suburban) rail transit in medium-sized cities [J]. Modern Urban Transit, 04 ,16 (2021).

3. Li Fumin, Zong Chuanling, Gao Long. Thinking about the planning and construction of urban rail transit [J]. Urban Transport of China, 19, 1 (2021).

4. The Fourteenth Five-Year Plan: We will accelerate the construction of urban (suburban) railways and promote the orderly development of urban rail transit [J]. China Metros, 3, 6 (2021).

5. Xu Yajie, Chen Xiangsheng. Quantitative analysis of spatial vitality and spatial characteristics of urban underground space (UUS) in metro area[J]. Tunnelling and Underground Space Technology incorporating Trenchless Technology Research, 111 (2021).

6. Su Yinglin. Safety risk control measures of urban rail transit engineering construction $[\mathrm{J}]$. Sichuan Building Materials,47,221 (2021).

7. Li Zhonghui, Xia Tongshui, Xia Zhiqing, Wang Xinjun, Ding Shihong. The Impact of Urban Rail Transit on Industrial Agglomeration Based on the Intermediary Effects of Factor Agglomeration[J]. Mathematical Problems in Engineering, 2021 (2021).

8. Xue Yitong. Analysis on the quality and safety management situation of rail transit construction project [J]. Construction Quality, 39, 3 (2021).

9. Ge Yingxi, Wang Beibei. Predicting the impact of urban rail transit construction on employment attractiveness based on the GM $(1,1)$ model: A case study of Guangzhou[J]. IOP Conference Series: Earth and Environmental Science, 647 (2021).

10. Pan Zhaoyu. Research on the key issues of urban rail transit planning and construction [J]. Urban Rapid Rail Transit, 33, 7 (2021).

11. Cheng Wenwen. The "fourth city" of rail transit -Chengdu Metro has entered the era of large line network [J]. Transport Construction \& Management, 6, 124 (2020). 